\title{
Qualities and Attributes of Successful Veterinary School Applicants
}

\author{
Stephen McBride
}

Department of Agriculture, Geosciences, and Natural Resources, The University of TennesseeMartin 256 Brehm Hall, Martin, TN 38238, USA

Tel: 1-731-881-7222Ｅ-mail: stemmcbr@ut.utm.edu

Danny Walker

Department of Agriculture, Geosciences, and Natural Resources, The University of TennesseeMartin 256 Brehm Hall, Martin, TN 38238, USA

Tel: 1-731-881-7328 E-mail: dwalke41@utm.edu

Jason Roberts

Department of Agriculture, Geosciences, and Natural Resources, The University of TennesseeMartin

256 Brehm Hall, Martin, TN 38238, USA

Tel: 1-731-881-1071 E-mail: jroberts@utm.edu

Joey Mehlhorn (Corresponding author)

Department of Agriculture, Geosciences, and Natural Resources, The University of TennesseeMartin

256 Brehm Hall, Martin, TN 38238, USA

Tel: 1-731-881-1071 E-mail: mehlhorn@utm.edu

Received: July 23, 2017

doi:10.5296/jet.v4i2.11753
Accepted: July 19, 2017

Published: August 20, 2017

URL: http://dx.doi.org/10.5296/jet.v4i2.11753

\begin{abstract}
This study was conducted from the fall of 2014 until the fall of 2016 with the purpose of exploring the common traits found in successful applicants to veterinary school. The study sought to answer the research question, "What should a student who wishes to become a veterinarian focus on and engage in today to ensure they are on a pathway to success in this profession?" A survey was distributed to students in pre-veterinary classes at the University
\end{abstract}


of Tennessee at Martin to gather data with the intention of determining common traits of certain variables. The categories in the survey were general information, career goals, expectations, and academic or personal skills. Once the surveys were returned, data was calculated in Microsoft Excel and compared with similar statistics in the veterinary field. Results showed that $84.5 \%$ of the students intend to apply to veterinary school. Additionally, $59.2 \%$ either grew up on a farm or have worked on a farm before and $64.1 \%$ had work experience at a veterinary clinic. When considering involvement in a youth leadership organization, 79.6\% indicated that they were a part of at least one at some point prior to their completion of the survey. Eighty percent of veterinary schools indicate they place a stronger emphasis on experience over strictly academic performance. Therefore, future applicants should compare their qualities with what veterinary school committees look for in candidates to determine whether they are on a pathway toward success in this field of study.

Keywords: Veterinary Medicine Applicants, Soft Skills, Student Success, Pre-Vet Programs

\section{Introduction}

Each year in classrooms across the nation, countless animal-loving, young students exclaim they want to pursue a career in veterinary medicine. In most cases, high school guidance counselors and parents serve as the gatekeepers of their fate in this field. Some will encourage these students to take on more challenging science curriculum and get involved in extracurricular organizations, while others steer them away from such goals. Those students who continue down this pathway as they begin college may end up having a change of heart or find certain coursework hindering their academic eligibility for graduate school. Although many are filtered away before they achieve an undergraduate diploma, each year nearly 6,000 students will apply to one of the 30 accredited veterinary schools in the United States (Wynne, 2016).

Almost half of all students who apply nationwide end up attending a veterinary school (Buss, 2016). Therefore, students must discover how to improve their application and interview scores to be competitive, or simply choose a new career altogether. How can one of those animal-loving young veterinary hopefuls better prepare themselves for success? Burns et al. (2006) suggest an emphasis on professional training, while Kogan and McConnell (2001) along with Lloyd et al. (2003) believe the nontechnical skills, knowledge, aptitudes, and attitudes of veterinary hopefuls provide the most aid in acceptance. Furthermore, the research of McConnell and Kogan (2001) details a study from Colorado State University, which concluded that subjective criteria should be the sole method of selecting their veterinary school candidates.

If the research shows a direct correlation between certain traits of applicants and their acceptance into veterinary school, then those findings should be helpful for future classes of high school and college students to position themselves for a higher trajectory toward their goal. Therefore, the objective of this research was to examine the competencies a prospective veterinary student should focus on now to find success in their application process to veterinary school. 


\section{Literature Review}

In Kogan and McConnell's (2001) research on gaining acceptance into veterinary school, it was evident that admissions committees found it difficult to ensure the students they selected were the best fit for successful careers in veterinary science. Before their study was conducted, academia was the largest, and in some cases the only, concern for applicants' acceptance and, thus, the gatekeepers of the medical and veterinary fields were those on admissions committees at each school. Obviously, the policies for admission must be fair and effective, therefore the criteria evaluated should be representative of what attributes will be most useful for completing their training successfully.

The Graduate Record Examination (GRE) is a requirement for most veterinary schools in the U.S., however, the researchers in this study found that relying solely on such standardized tests can cause otherwise impressive candidates to be rejected. Some graduate schools have even offered to waive examinations for certain exceptions. For instance, if a student agrees to work in a rural area after graduation, the Texas A\&M School of Medicine will waive their Medical College Aptitude Test (MCAT) requirement. In fact, at the time of this study, Texas had a new law go into effect making it illegal for graduate schools to reject students strictly based on their standardized test scores (Kogan \& McConnell, 2001).

McConnell and Kogan (2001) collaborated again with their study of subjective criteria as the sole method of selecting veterinary candidates. They indicated that admission committee members must choose students who have the highest potential for success in academia and as professionals with the lowest chance of failure. Confer et al. (1995) continued one step further by stating to predict a student's success, a combination of their academic performance, test scores, and subjective criteria will give a more accurate reading than any one of these by itself.

Many studies have concluded that non-cognitive skills are just as, if not more, important as cognitive abilities to a candidate's success in the veterinary field. McConnell and Kogan (2001) found that pet owners would consider the personality and empathy of their veterinarian to be of utmost importance. In fact, some studies have shown clinical performance to be more closely linked to personality than academics. Taking this into consideration, many schools have emphasized non-cognitive abilities such as leadership, work experience, and people skills in their selection of viable candidates (McConnell \& Kogan, 2001).

A Colorado State study made a list of the qualities that an outstanding veterinarian possesses. Some of which include service such as mentorship or 4-H involvement, leadership skills evident in sports or FFA, social skills from interacting with others, knowledge of the veterinary profession from hands-on experience in a veterinary clinic, and communication skills found in their essay writing abilities. Since transitioning to this more subjective admissions process, Colorado State has been able to include the non-cognitive skills that affect performance and success in selecting the most well-rounded students into their College of Veterinary Medicine and Biomedical Sciences (McConnell \& Kogan, 2001). 
Lloyd et al. (2003) reviewed the results from the Personnel Decisions International (PDI) study for their national workshop on the Core Competencies for Veterinary Medicine. It was apparent in the research that students' nontechnical skills, knowledge, aptitudes, and attitudes were not adequately prepared for their economic success as veterinary professionals. Like the Colorado State research, this study found interpersonal, self-management, leadership, communication, business, and thinking as six vital non-technical competencies for success. With so much coursework involved in veterinary school and so little time for extracurricular training, some requirements would ideally be developed beforehand. In this workshop study, it was suggested that experiences before a student's application to veterinary school could be a great chance to develop some of these non-technical competencies (Lloyd et al., 2003).

As quoted by Kogan and McConnell (2001), "By including non-cognitive criteria in the admissions process, schools are better able to eliminate applicants who appear qualified from the standpoint of academic standards but are likely to be poor students, or poor doctors, because of emotional, motivational, or attitudinal problems." Likely, including both cognitive and non-cognitive criteria will more accurately predict veterinary or medical school success, and those who score well in the areas of non-cognitive abilities in their interview are more likely to have better clinical ratings than those who do not. Additionally, Burns et al. (2006) calls for non-technical competence to be taught in the veterinary school curriculum. This study highlights the fact that although technological advances have revolutionized the veterinary and medical fields, people skills have not kept pace. The non-technical core competencies are so lacking that the growth and satisfaction of veterinarians could very well be endangered. Considering this as a possibility, their research suggests communication, leadership, and relationship skills training should be a focus during veterinary school to give these students practice before entering the workforce. Without these skills, professional performance could suffer (Burns et al., 2006).

The Washington State University Cougar Orientation and Leadership Experience (COLE) prepares students for academic and professional success before diving into their graduate school curriculum. With a focus on leadership and teamwork, COLE enables students to realize the importance of non-technical skills in their profession, however such skills cannot be taught at one single event. In fact, possibly seven or eight such experiences could be necessary for the development of a lasting change in behavior. Part of the Washington State curriculum reminds students of the personal and interpersonal damages that could occur from focusing too much on studying material and neglecting non-technical development (Burns et al., 2006).

Rush et al. (2005) would argue that a student has far more difficulty academically in graduate school and should, therefore, focus on their studies. However, this philosophy fails to realize the need for a balanced education in veterinary and medical school. A quote from Burns et al. (2006) provides a well-worded summary of this research project, "....although the medical and scientific skills of our graduates remain high, the addition of non-technical training will only enhance the professional quality, marketability, and success potential of our future doctors of veterinary medicine." 


\section{Methods}

The study was conducted from the fall of 2014 until the fall of 2016 at the University of Tennessee at Martin's College of Agriculture and Applied Sciences. The purpose of collecting data through surveys was to explore the common traits found in applicants who aspire to apply to veterinary school. The protocol was approved by the University of Tennessee at Martin Institutional Review Board, Docket Number 15-354-E05-4005, and informed consent was obtained from each subject prior to their completion of the survey.

The twenty-seven question survey was formulated with specific data questions pertinent to the comparison of current UT Martin students with the qualities and attributes most desired by veterinary school committees. The categories were general information, career goals, expectations, and academic or personal skills. Specific questions included the students' major, intentions to apply to veterinary school or not, agricultural backgrounds, veterinary clinic work experience, youth leadership involvement, influences, career goals as a veterinarian, undergraduate expectations and feedback, as well as study habits and academic skills.

\section{Results and Discussion}

While most of the journals used for research on this topic were published roughly fifteen years ago, it is important to note the changes that have been made to veterinary school entrance criteria since then. Prior to these studies, virtually the only qualities that were important to a student's acceptance were GRE scores, MCAT or Veterinary College Aptitude Test (VCAT) scores, and undergraduate GPA. Today, each veterinary school requires a certain level of non-technical skills and development for acceptance (Wynne, 2016). These include extracurricular involvement, experience working at a veterinary clinic with animals and customers, leadership and communication skills, and many more.

\subsection{Application Process to Veterinary Medical School}

Most U.S. veterinary schools have adopted a balanced rubric to evaluate their candidates based upon equal emphasis on prerequisite coursework and entrance exam scores as well as their professional skills. These are evaluated based upon the application which includes transcripts, resumes, and essays, and although some require an interview others do not. For instance, some schools will require only in-state applicants to interview while the University of Georgia has no interview process for any candidate (Wynne, 2016).

While a resounding number of journal articles, essays, and theses agree certain developments are needed for students' professional development, there were little to no arguments for the alternative viewpoint. Of course, a well-rounded individual is ideal, but perhaps Rush et al. (2005) were on to something in their research of students' grades. Non-technical and professional development are essential, but without a proper focus on academics, students will not be successful in their field. There must be a balance. 


\subsection{Undergraduate Pre-Veterinary Survey}

Of the 103 surveyed, $15.5 \%$ were male and $84.5 \%$ were female. Per the Veterinary Medical College Application Service (VMCAS), in the early 1970s veterinary school enrollments were male-dominated by almost $90 \%$; however, the number of female applicants has been on the rise since the late 1980s. In 2016, 17.4\% of all applicants nationwide were male and $82.6 \%$ were female (Wynne, 2016). This number is consistent with the pre-veterinary ratio at UT Martin, as shown in Figure 1. Sixty-three percent of the UT Martin students surveyed were freshmen, which will be useful in assisting some of the students in improving their coursework, work experience, and leadership skills, between now and their intended application date. The majority, $67.3 \%$, of students are pre-veterinary majors, while $18.8 \%$ are animal science and $13 \%$ are veterinary technician degree candidates. Of all these students, $84.5 \%$ who intend to apply to veterinary school.

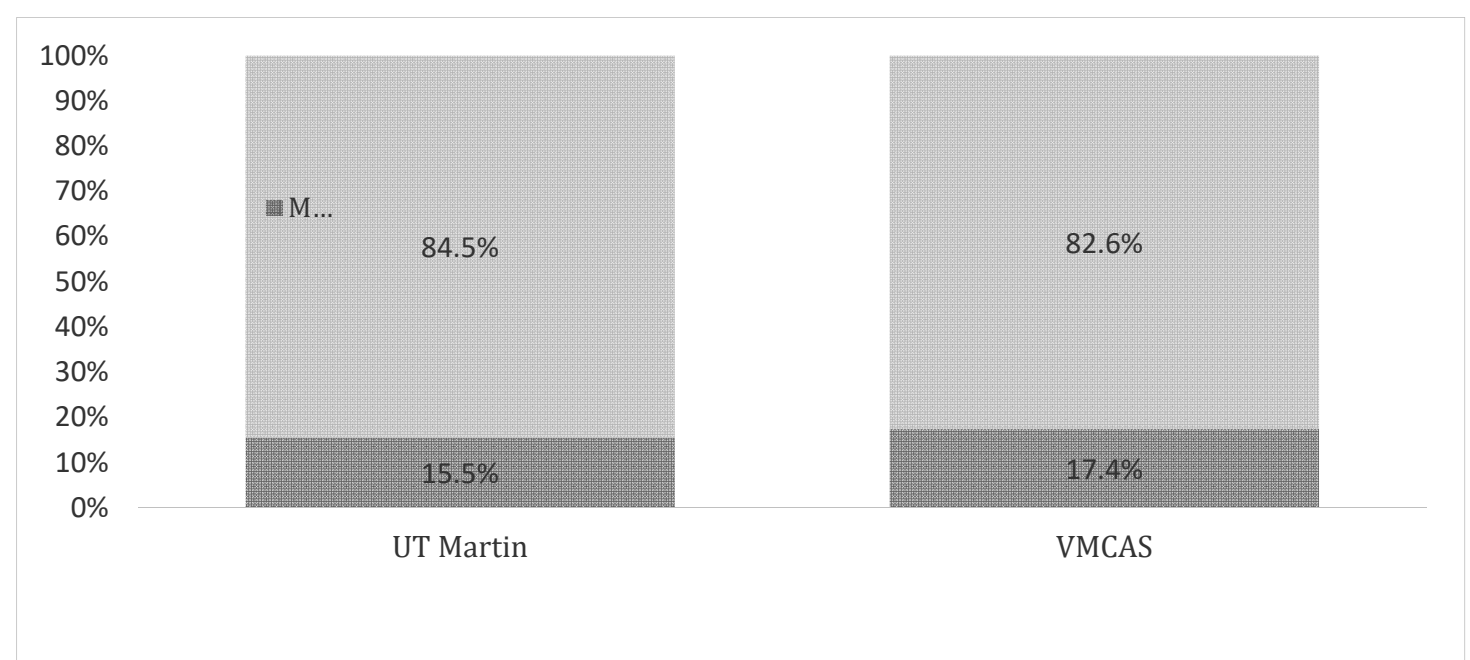

Figure 1. Comparison of applicants' gender at UT Martin with VMCAS (Wynne, 2016)

\subsection{Undergraduate Background Experiences}

Most, 59.2\%, of the surveyed students have experience working on a farm and $64.1 \%$ have worked or volunteered at a veterinary clinic. Figure 2 below distinguishes more than $79.6 \%$ have been involved in a youth leadership organization with 45 FFA members, 43 4-Hers, and 22 HOSA members. The rest of the students were involved in HOSA, SkillsUSA, DECA, or another organization such as BETA, Key Club, or the Scouts, while 21 students out of 103 indicated they had not been involved in any youth leadership organization. 

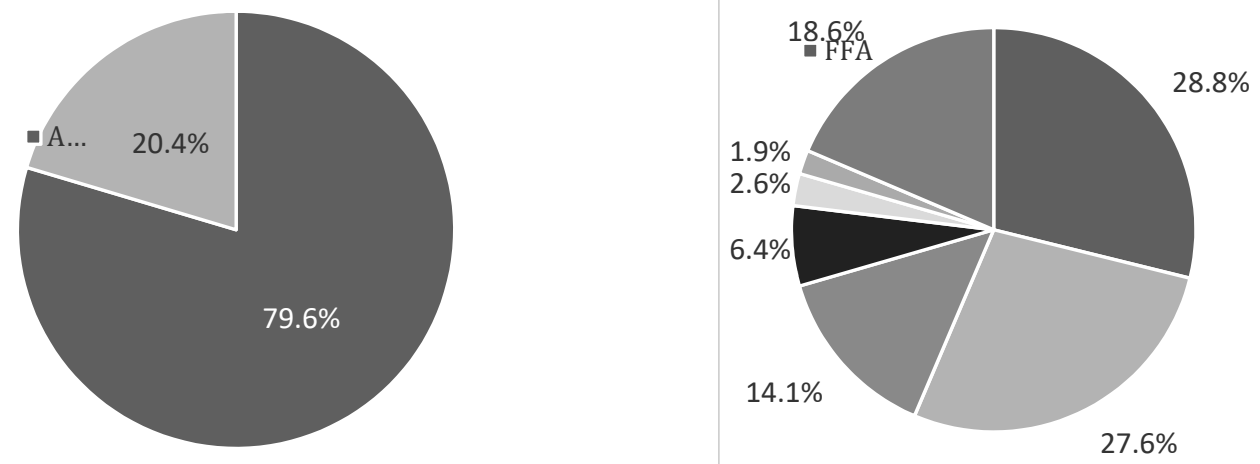

Figure 2. Breakdown of (a) students' involvement in youth leadership organizations and (b) the one's in which they are active

More than half of the students decided to study veterinary science because the career interests them, while a third decided because of the day-to-day lifestyle of a veterinarian, and only $15.7 \%$ said it was for the money. When asked about their planned career goal, $87.6 \%$ noted their intention to work in a large or small animal clinic or a mixed practice, while $7.2 \%$ want to work in a zoo and 5.2\% would like to continue toward the field of academia or research. This is broken down below in Figure 3 and Table 1.

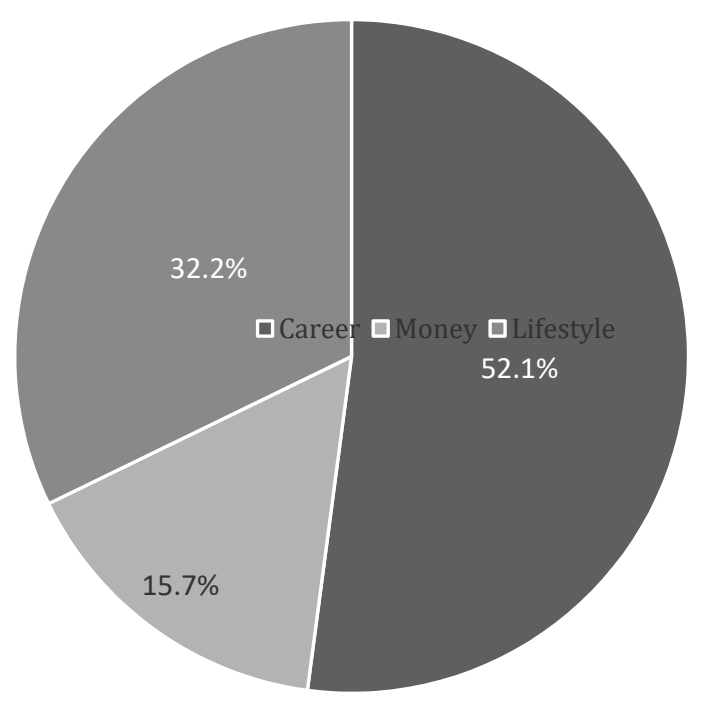

Figure 3. Contrast of different pathways to this major for undergraduates. 
Table 1. Division of career goals in the veterinary field

\begin{tabular}{|c|c|c|c|c|}
\hline Large Animal & Small Animal & Mixed Practice & Zoo & Academia/Research \\
\hline $22.7 \%$ & $15.4 \%$ & $49.5 \%$ & $7.2 \%$ & $5.2 \%$ \\
\hline
\end{tabular}

Interestingly, a surprising $29.4 \%$ of students who indicated their intention to apply to veterinary school had no experience working at a veterinary clinic at all. Twenty-five of the 30 veterinary schools in the United States require work experience for entrance into their program. Auburn requires a minimum of 400-hours experience, while Penn requires 500-600-hours (Wynne, 2016). University departments preparing undergraduate students for application to veterinary medicine programs should continue to stress the importance of this area for pre-veterinary students as they plan their careers.

Nineteen states have a contract agreement with certain veterinary schools across the country (Wynne, 2016). These applicants will be given priority and are eligible for lower tuition costs than regular non-resident applicants. In fact, the average veterinary school tuition is $\$ 29,561.07$ for resident applicants and $\$ 49,219.90$ for non-resident applicants. The exact numbers for each school's annual tuition cost for resident and non-resident students is detailed below in Figure 4. Louisiana State University charges the most for both resident and non-resident applicants at $\$ 54,648$ and $\$ 83,748$ respectively. North Carolina State University charges the least for in-state residents at only $\$ 18,138$. Their non-residents pay $\$ 42,952$, but are eligible to apply for residency tuition after the first year of veterinary school (Wynne, 2016).

Per Lloyd and Walsh (2002), when a veterinarian is fiscally successful, then he or she will have a higher capacity to provide consistent and quality care and benefit the welfare of their animals, owners, and society. Therefore, students who wish to apply to veterinary school should study the requirements and tuition at each school they are interested in to determine which one is the right fit for them.

Some veterinary hopefuls may be unaware of the contract or resident agreements that a veterinary school may have with their state where they would be given priority in the interview process. Additionally, certain schools may not have been on a student's radar, but could turn out to be the most economically efficient choice for their field of study. The median overall indebtedness of veterinary graduates has increased from $\$ 106,063$ in 2006 to $\$ 156,583$ in 2015 (Wynne, 2016). With so many veterinary professionals deeply in debt, the most cost efficient veterinary program would be the most beneficial for applicants to consider. 


\section{Macrothink}

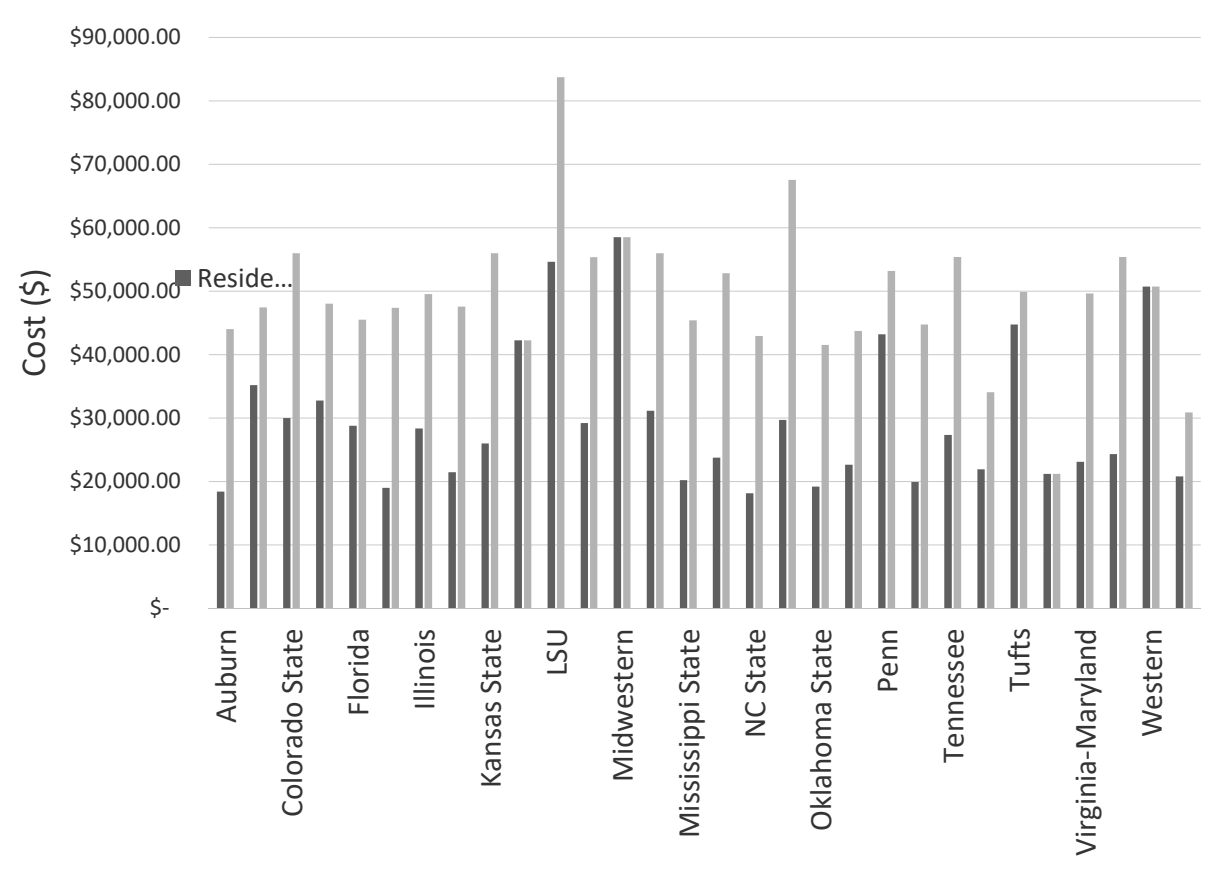

Figure 4. Comparison of each veterinary school's resident and non-resident annual tuition.

\section{Conclusions}

This project discovered common traits found in successful veterinary school applicants to include a mixture of cognitive and non-cognitive developments and skills. The study found that students who wish to become veterinarians should focus on developing their professional skills to ensure they are on a pathway to a successful career as a veterinarian. If a student desires to pursue a career in veterinary medicine, they would benefit greatly from getting involved sooner, rather than later, in extracurricular activities and organizations such as 4- $\mathrm{H}$, FFA, or a veterinary club at their school or in their community. Also, students should consider the financial undertaking of certain veterinary programs and consider the one that is most economical for them.

Veterinary school committees must determine whether a student will be successful by analyzing the traits each applicant possesses. Changes in the thought process of committee members over the years has led to a more accurate reading of candidates and a higher rate of graduation (Wynne, 2016). UT Martin's veterinary science program has found success over the last decade in having increased applicants accepted into veterinary school through increased emphasis on extracurricular traits. The research of this project confirmed that success with many undergraduate students already on the right path with their cognitive and non-cognitive development. Active involvement in a veterinary clinic, academic courses, and youth leadership organizations will be the key for students to shine in their application process. There is a need for more research to be conducted on traits of successful veterinary applicants. Future research would benefit from additional surveys current veterinary school students along with admissions committees to assess how the process is changing. 


\section{Acknowledgement}

The research was conducted as part of an undergraduate scholar's project funded through the University Scholars Program at the University of Tennessee at Martin. Special thanks to Lionel Crews for his support.

\section{References}

Burns, G. A., Ruby, K. L., DeBowes, R. M., Seaman, S. J., \& Brannan, J. K. (2006). Teaching Non-Technical (Professional) Competence in a Veterinary School Curriculum. Journal of Veterinary Medical Education, 33(2), 301-308. doi:10.3138/jvme.33.2.301

Buss, D. D. (Ed.). (2016). Media FAQs. Retrieved from http://aavmc.org/Media-FAQs.aspx

Confer, A. W., Turnwald, G.H., \& Wollenburg, D.E. (1995). Correlation of Objective and Subjective Admission Criteria with First Year Academic Performance. Journal of Veterinary Medical Education, 20(3), 14-25

Glick, S. M. (1994). Selection of medical students: The Beer-Sheva perspective. Medical Education, 28(4), 265-270. doi:10.1111/j.1365-2923.1994.tb02710.x

Kogan, L. R., \& McConnell, S. L. (2001). Gaining Acceptance into Veterinary School: A Review of Medical and Veterinary Admissions Policies and Practices. Journal of Veterinary Medical Education, 28(3), 101-110. doi:10.3138/jvme.28.3.101

Lloyd, J. W., King, L. J., Klausner, J. S., \& Harris, D. (2003). National Workshop on Core Competencies for Success in the Veterinary Profession. Journal of Veterinary Medical Education, 30(3), 280-284. doi:10.3138/jvme.30.3.280

Lloyd, J. W., \& Walsh, D. A. (2002). Template for a Recommended Curriculum in "Veterinary Professional Development and Career Success". Journal of Veterinary Medical Education, 29(2), 84-93. doi:10.3138/jvme.29.2.84

McConnell, S. L., \& Kogan, L. R. (2001). Subjective Criteria as the Sole Method of Selecting Veterinary Candidates at a US Veterinary Medical School. Journal of Veterinary Medical Education, 28(3), 131-135. doi:10.3138/jvme.28.3.131

Rush, B. R., Sanderson, M. W., \& Elmore, R. G. (2005). Pre-matriculation Indicators of Academic Difficulty during Veterinary School. Journal of Veterinary Medical Education, 32(4), 517-522. doi:10.3138/jvme.32.4.517

Wynne, T. (Ed.). (2016). Veterinary Medical School: Admission Requirements (2016 ed.). West Lafayette, IN: Purdue University Press.

\section{Copyright Disclaimer}

Copyright reserved by the author(s).

This article is an open-access article distributed under the terms and conditions of the Creative Commons Attribution license (http://creativecommons.org/licenses/by/3.0/). 